\title{
A Review on Optimizations of Welding Parameters in GMA Welding Process
}

\author{
Ill-Soo Kim*,†, and Min-Ho Park* \\ *Department of Mechanical Engineering, Mokpo National University, Mokpo, 58554, Korea. \\ †Corresponding author : ilsookim@mokpo.ac.kr \\ (Received October 11, 2017 ; Revised November 10, 2017 ; Accepted December 20, 2017)
}

\begin{abstract}
With the increase of automatic welding system employed in the manufacturing industries, the selection of optimal welding parameters must be more specific to ensure that quality is obtained. Furthermore, it is necessary to have a suitable model that establishes the interrelationship between welding parameters and bead geometry to get the desired weld ability as quality since it is a complicated process, which involves interactions of thermal, mechanical, electrical and metallurgical phenomenon. Many researchers have reported theoretical, numerical, empirical and AI models to give the optimal welding conditions for GMA(Gas Metal Arc) welding process. In addition, controlling the welding parameters plays an important role in ensuring the quality of the weld. However, there is a need to comprehensively review the GMA welding process in terms of different independent and dependent welding parameters for the purpose of modeling and optimization of GMA process. In this paper, several experimental design and optimization methodologies are reviewed and discussed with current literature on experimental design, multiple regressions analysis, the neural network, fuzzy logic, and genetic algorithm to improve the quality of weldments. This review underlines the need of development of appropriate nature inspired algorithm for the optimization of such advanced manufacturing process.
\end{abstract}

Key Words : GMA(Gas Metal Arc) welding process, Optimization, Welding parameters, Bead geometry

\section{Introduction}

Generally GMA welding process is today accepted as the preferred joining technique and commonly chosen for assembling most large metal structures such as automotive, aircraft and shipbuilding due to its joint strength, reliability, and low cost compared to other joint processes $^{1)}$. The demand to increase productivity and quality, the shortage of skilled labor and safety requirements finally led to the development of the automatic GMA welding process to deal with many of the present problems of the welded fabrication. Recently, a new way of thinking to meet the global competition and the survival of products in the market, is concentrated on improving the existing technology and developing products at economical price. It means not only to invest in developing the new equipment, but also to effectively control the welding parameters involved in any manufacturing process. Those welding parameters must be measured, controlled and optimized to get the desired and valuable outputs as those parameters vary for the different type of the arc welding process chosen. Optimization depends upon the ability to measure and control the welding parameters involved in GMA welding process ${ }^{2)}$.

Consequently, incorrect settings of those welding parameters give rise to deviations in the welding characteristics from the desired bead geometry. With the advance of the automated GMA welding process, processing optimization which selects the welding procedure and predicts bead geometry that will be deposited, has been increased. A major concern involving optimizations should define a welding procedure which can be shown to be the best with respect to some standard and chosen combination of welding parameters which give an acceptable balance between production rate and the scope of defects for a given situation ${ }^{3)}$. Typical welding optimization can be established by making a record of all the welding parameters, defining a critical range, and specifying desired parameter values. 
Several models ${ }^{4-9)}$ which can be programmed easily and fed to the robot, should be developed to make effective use of GMA welding process. It should also give a high degree of confidence in predicting the bead dimensions and shape to accomplish the desired mechanical properties of the weldment. Those models to control welding quality, productivity, micro-structure and weld properties in GMA welding processes have been studied ${ }^{7)}$. However, it is not an easy task to apply them for the various practical situations because not only the relationship between the welding parameters and the bead geometry is non-linear, but also they are usually dependent on the specific experimental results ${ }^{10)}$. Practically, it is important to know how to establish a model that can apply for the actual GMA welding process and how to select the optimum welding condition under a certain constraint.

In this paper, a comprehensive literature review of these techniques to study interrelationship between input and output parameters and to optimize the welding parameters on the final weld quality by various experimental techniques for GMA welding process was presented. A brief discussion on recent publications on experimental, empirical and AI techniques by different researchers is also included. To fully understand the influence of welding parameters on bead geometry in GMA welding process in this paper, not only experimental design and multiple regression analysis but also neural networks, fuzzy logic theory and genetic algorithm were employed to investigate relationship between the welding parameters and bead geometry, and to give information for selecting the best algorithm model to control the bead geometry as weld quality. Every effort has been made to cite the most recent developments.

The review of a variety approaches developed would help to compare their main features and their relative restrictions to allow choosing the most suitable algorithm for a particular application.

\section{GMA Welding process}

\subsection{Welding Parameters}

GMA welding process, one of the oldest and fastest growing metal joining processes, has been an important component in Korea's economy because of the progress made in welding equipment, wires and design. The method, sometimes called Metal Inert Gas(MIG) welding process, is a welding process which yields coalescence of metals by heating with a welding arc between a continuous filler metal(consumable) wire and the workpiece ${ }^{11)}$. The continuous wire wire which is drawn from a reel by an automatic wire feeder, and then

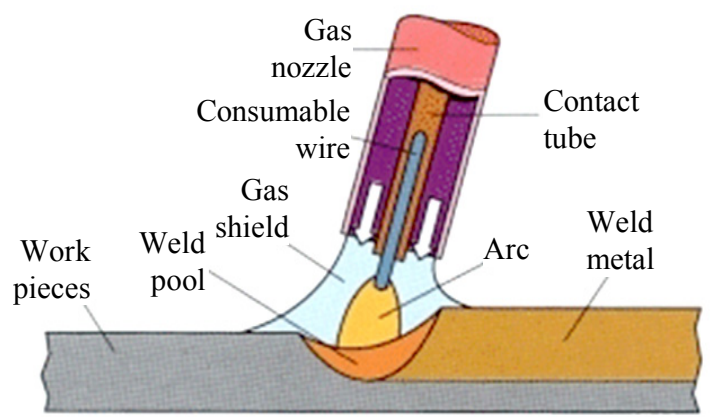

Fig. 1 Experimental setup for bellows plasma welding ${ }^{11)}$

fed through the contact tip inside the welding torch, is melted by the internal resistive power and heat transferred from the welding arc. As shown in Fig. 1, heat is concentrated by the welding arc from the end of the melting wire to molten weld pools and by the molten metal which is being transferred to weld pools. Molten weld pools and wire wire are protected from contaminants in the atmosphere by a shielding gas obtained from an externally supplied $\mathrm{Ar}, \mathrm{CO}_{2}$, or mixtures $\mathrm{Ar}$ with $\mathrm{O}_{2}, \mathrm{H}_{2}, \mathrm{He}$, or $\mathrm{CO}_{2}$ in various combinations ${ }^{12)}$. Applications of the GMA welding process have ranged from joining thin section pipelines to assembling large metal structures such as pressure vessels, bridges, cars, trains and nuclear reactors.

However, a major difficulty in the procedure optimization is many welding parameters involved. The welding parameters which could affect bead geometry and overall weld quality during the GMA welding process could be classified into three categories ${ }^{13)}$. For achieving satisfactory bead geometry and studying the effects of those parameters which definitely affect the metal transfer mode and the amount of heat input to the workpiece, it is essential to control the above welding parameters. Welding parameters in GMA welding process are generally welding current, polarity, arc voltage, welding speed, wire extension, wire orientation, weld joint position, wire diameter, shielding gas composition, gas flow rate, material composition and material thickness. Furthermore, relationships between welding parameters and the bead geometry are complex so that the required control system will be dependent on a realistic model of the GMA welding process because the welding parameters are interdependent and the effect of one welding parameter might affect another ${ }^{14)}$.

wire type and shielding methods are usually the basic considerations and dictated by the required weldment mechanical properties. wire size is related to bead geometry, while the welding current is recommended for a particular job and the number of passes. wire polarity is 
initially established and based on whether maximum penetration or maximum deposition rate is required. Weld pool shape and magnitudes depend on the heat input involved that in turn, relies upon welding parameters $^{15)}$. Welding current and welding speed dominate the bead penetration for single pass welds. The selection of welding current and welding speed are based on wire size. Furthermore, arc voltage which dominates the bead width, has an influence on the bead penetration since it controls the arc shape ${ }^{16)}$. A controller in the automatic GMA welding system is used to control wire feed rate, arc current and welding voltage. In some cases, it is also employed to control the gas flow rate ${ }^{17}$.

Since the wire feed rate and arc length are controlled by the power source, but the travel speed and wire position are under manual control, the welding process is often referred as a semi-automatic process, The process can also be mechanized when all the welding parameters are not directly controlled by a welder, but might still require manual adjustment during welding. When no manual intervention is needed during GMA welding process, the process can be referred to as automatic. Consequently, trainee welders are referred to the tabulated information relating different metal types and thickness to recommend the desired values of welding parameters $^{18)}$.

\subsection{Bead Geometry}

Basically, the bead geometry plays an important role in determining the GMA mechanical properties of the weld. So it is very important to select the welding parameters for obtaining optimal bead geometry. However, it is difficult for the traditional identification methods to provide an accurate model because the optimized welding process is non-linear and time-dependent ${ }^{19)}$. Generally, bead geometry for GMA welding process depends on the amount and distribution of the input energy on the workpiece surface ${ }^{20-21)}$. In the GMA welding process, heat and mass inputs are coupled and offered by the welding arc to weld pools and by the molten metal which is being transferred to weld pools as indicated in Fig. 2. The amount and distribution of the input energy are basically controlled by the distinct and cautious choice of welding parameters to achieve the optimal bead geometry and the desired mechanical properties of the weldment.

$\mathrm{Kim}^{22)}$ tried to study the classification of bead geometry for GMA welding process in details. Fig. 3 gives a schematic representation with definition of bead dimensions. Also, he investigated the effects of the welding parameters on the resultant GMA welding, a number of output parameters called bead geometry were measured

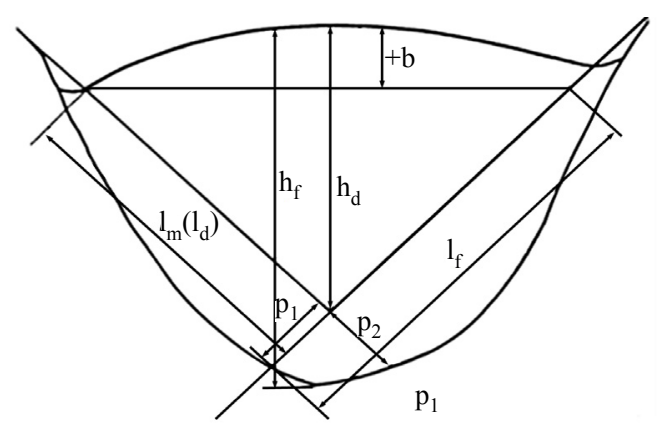

Fig. 2 Definition of dimensions for GMA welding process with flux cored wires ${ }^{21)}$

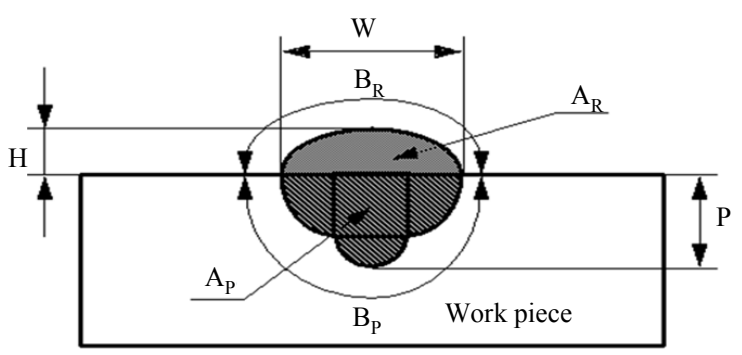

Fig. 3 Definition of bead dimensions ${ }^{22)}$

from the specimens of the workpiece. A definition of bead geometry, as the basic of a control system for the automatic GMA welding process, describes its shape and derives other dimensions which should be meaningful in determining the acceptability of the weld. These parameters also determine the basic mechanical properties of the weld and the basic stress handling capabilities of the joints. In such automated applications, a precise means of selection of the welding parameters and control of bead geometry has become essential because mechanical strength of weld is influenced not only by the composition of the metal, but also by the bead shape $^{23)}$.

The acceptable bead geometry depends on factors such as line power which is the heat energy supplied by an arc to the base plate per unit length of weld, welding speed, joint preparation, etc. This may be achieved by the development of mathematical expressions, which can be fed into a computer, relating the bead dimensions to the important welding parameter affecting these dimensions 24-26). Also, optimization of the welding parameters to control and obtain the required shape and quality of weld beads is possible with these expressions.

\section{Optimization of Welding Parameters}

\subsection{Experimental Design}

In experiments with many factors, each combination 
of the levels of the factors is referred to as a treatment. When the same numbers of response observations are taken for each of the treatments of an experiment, the design of the experiment is said to be balanced ${ }^{27-28)}$. In full factorial experiments, all of the factors and their interactions are investigated, whereas all interactions in fractional factorial experiments, are not considered because not all treatment combinations are run. In addition, the orthogonal property is important since it eliminates correlation between the estimates of the main effects and interactions ${ }^{29}$. To reduce the number of experiments to a practical level, only a small set from all the possibilities is selected. The method of selecting a limited number of experiments which produces the most information is known as a partial fraction experiment. Although this method is well known, there are no general guidelines for its application or the analysis of the results obtained by performing the experiments.

Many efforts ${ }^{30}$ for optimization of GMA welding process have been done to develop the analytical and numerical models to study these relationships, but it were not an easy task because there were some unknown, nonlinear welding parameters. For this reason, it is good for solving this problem by the experimental models. One of the experimental models was a factory design that was utilized to establish the empirical models for various arc welding processes ${ }^{30-31)}$. Datta et al. ${ }^{32)}$ employed a 33 full factorial design, have been conducted with 3 levels of 3 welding parameters: welding current, welding voltage, and wire extension. The analysis of variance(ANOVA) was employed to evaluate quantitatively the significant of the main and interaction effects of 3 welding parameters on bead volume.

The effects of welding parameters were also represented graphically and it is shown that these welding parameters were to represent significant effects on bead volume. The main and interaction effects of the welding parameters on bead geometry was determined quantitatively and presented graphically. Furthermore, Gunaraj et al. ${ }^{33-34)}$ employed was designed based on a four factor five level factorial central composite rotatable design. ANOVA analysis was effectively used to test the adequacy of the all the developed models. Recently, the Taguchi method has become the most powerful tool for improving productivity, quality, and at the same time reduce development interval during research and development ${ }^{35)}$. The technique of laying out the conditions of experiments involving multiple factors was first proposed by Hargopal et al. ${ }^{36)}$.

Also, the method ${ }^{37)}$ has been developed a set of techniques based on statistical principles and utilized engineering knowledge as shown in Fig. 4. This method-

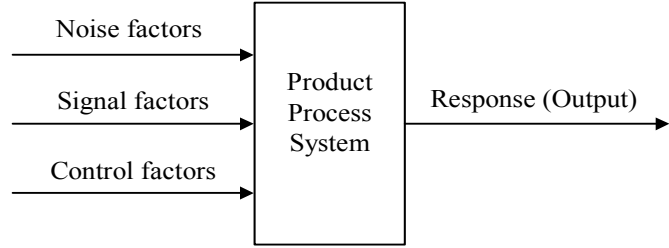

Fig. 4 Parameter diagram of a product process system ${ }^{16)}$

ology uses a special set of arrays called orthogonal arrays as an effective experimental design tools for greatly reducing the size of experiments while still achieving new insights as well as improving product designs and process productivity. In order to measure the quadratic loss function, Taguchi introduces the signal-to-noise $(\mathrm{S} / \mathrm{N})$ ratios for measuring the quality through orthogonal array based experiments so that he most economical experimental design in terms of high accuracy and fast convergence speed at the smallest development cost can be accomplished. A class of statistics called $\mathrm{S} / \mathrm{N}$ ratios has been defined to measure the effect of noise factors on performance characteristics. With the help of the Taguchi, optimization can be obtained and reduced a computer system's response time under a specified range of load and environmental conditions. This was achieved by simultaneously studying a large number of system parameters, not studying one parameter at a time ${ }^{38)}$.

Since the bead geometry plays an important role in determining the welding mechanical properties, Taguchi method is also recently used to achieve optimal geometry. Tarng et al. ${ }^{4)}$ employed Taguchi methods for the optimization of welding parameters in hardfacing with considerations of multiple weld qualities. Esme et al. ${ }^{39)}$ presented the selection of welding parameters by using Taguchi method for obtaining optimal bead geometry in the stainless. They also represented that this approach provides an effective means to enhance the prediction of the quality characteristics such as front- height, frontwidth, back-height and back-width of the weld pool. To consider several quality characteristics together, a weighting method ${ }^{40)}$ is proposed to integrate the loss functions of many welding parameters into overall loss function to solve the problem proposed above. The value of the overall loss function is further transformed into one $\mathrm{S} / \mathrm{N}$ ratio.

\subsection{Empirical Models}

Modeling of phenomena for the GMA welding process has been a major preoccupation over the years, and literature abounds with relationships between welding parameters and bead geometry as welding quality for the purpose of representing the essential aspects of a specif- 
ic system, in such a way that knowledge can be employed for the process optimization ${ }^{1)}$. A common approach to establish these values is through the trial and error method. Such a method is a time consuming and expensive process and can lead to the premature termination of the design process ${ }^{2}$. With the advance of the automatic GMA welding process, procedure optimization which selects the welding procedure and predicts bead geometry has been increased. Typical welding optimizations can be established by making a record of all the parameters, defining a critical range, and specifying desired parameter values ${ }^{20)}$.

An earlier attempt to welding optimization, called a tolerance box, was developed to preserve all the compiled information, to allow a rigorous determination of the effects on the quality of any modification of the welding parameters, and to offer a well-informed choice of the welding parameters in terms of the constraints imposed by the production process ${ }^{41}$. Nevertheless, this approach required a large number of tests, and was found to be impractical for process control purposes when dealing with more than three welding parameters. Such a work published before 1978 was summarized by Shinoda and Doherty ${ }^{15)}$. McGlone ${ }^{42)}$ and McGlone and Charwick $^{43)}$ reported the mathematical analysis of the relationship between welding parameters and bead geometry for square edge close butts. Similar mathematical relationship between welding parameters and weld geometry for the GMA welding has also been reported ${ }^{44-51)}$.

The situation has been altered recently with the advent of increasing computer efficiency and better understanding of the usefulness of statistically designed experimentation based on factorial techniques ${ }^{44)}$ which can reduce cost and provide the required information about the main and the interaction effects on the response factors. Such techniques for establishing relationship between welding parameters and bead geometry have been reported for the GMA welding process to accomplish control over arc behavior for fully automatic welding process. Multiple regression analysis, as one of the most important statistical techniques can be employed in the welding process control based on the analysis of the control parameters themselves ${ }^{45}$. The investigation of relationship between welding parameters and bead geometry as welding quality has begun in the mid-1900s, and regression analysis was applied to bead geometry research in 1987 by Raveendra and Parmer ${ }^{46}$. Chandel $^{47)}$ first applied this technique to the GMA welding process and investigated relationship between welding parameters and bead geometry of bead-on-plate welds deposited. Also, Yang et al ${ }^{48)}$ first extended their study to the weld deposit area and presented the effects of wire polarity, extension, wire diameter, welding current, arc voltage, travel speed, power source characteristics and flux basicity on the weld deposit area. The results of their experiment indicated that a small-diameter wire, long wire extension, low voltage and high welding speed produce a large deposit area, whereas the power source and flux type do not seem to have any significant effect on the weld deposit area. Recently, Park et al. ${ }^{49)}$ carried out to study relationship between the process parameters and the bead geometry.

The quantitative effect of welding parameters on bead geometry was calculated using sensitivity analysis, and thus critical parameters can be identified and ranked by their order of importance. Kim et al. ${ }^{50)}$ applied the effects of the welding parameters on the back-bead geometry in the vertical and overhead positions of pipe welding. The experimental results were employed to develop the empirical models to the selection of optimal welding condition for the root-pass welding and verity the significance in the developed empirical model. Kim et al. ${ }^{51)}$ performed the statistical analysis of a generalized regression approach which was conducted by using the linear regression response surface analysis to develop relationship between welding parameters and bead width as welding quality and showed the results as indicated Fig. 5.

\subsection{Neural Network Models}

Neural Network(NN), an information processing paradigm which is inspired by the biological nervous systems, is expected to be widely applied in vision, decision-making, signal processing, and quality control systems. Many important advances have been boosted by the use of inexpensive computer emulations. These pioneers were to develop convincing technology which surpassed the limitations identified by Minsky and Papert $^{52}$. In recent years, the neural network has become a very powerful technique to develop a model to express interrelationship between the input and the output of complicated systems ${ }^{2}$. The key benefit of a neural network in the domain of engineering design and group technology is its ability to store a large set of pa-
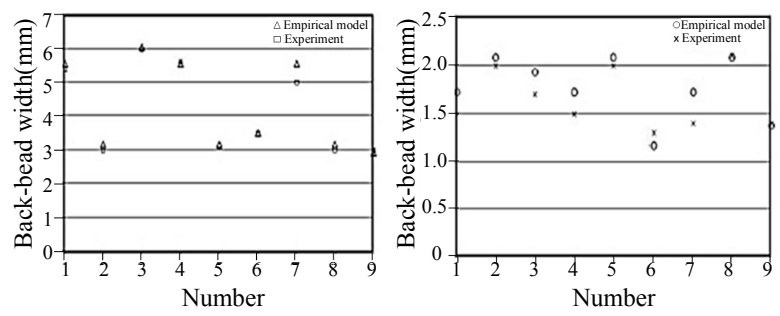

Fig. 5 Accuracy analysis for overhead position ${ }^{51}$ 
rameter patterns as memories for the system which can be later recalled.

As it is recalled, these memories will be excited with a key pattern containing information on a particular member of a stored pattern set. Additionally, the neural network has learning and generalization capabilities so that the prediction of the correlation between the input as the examples and the expected output can be established systematically. After a certain amount of training process, the neural network can generate appropriate output in response to new input ${ }^{53)}$. This capability guarantee the neural network to be a useful tool in many applications in the current manufacturing industry covering the design phase through control, monitoring and scheduling to quality assurance ${ }^{54)}$.

Many researchers ${ }^{55-61)}$ have attempted to employ the neural network to model the various applications in the arc welding area. Juang et al. ${ }^{55)}$ explored the back-propagation and counter-propagation networks to associate the welding parameters with the features of the bead geometry, and concluded that the counter-propagation network has better learning ability than the back-propagation network. Nagesh and Datta ${ }^{56)}$ applied the backpropagation neural network to predict the bead geometry. They claimed that the neural network constitutes a workable model to predict the bead geometry under a given set of welding conditions. Also, Li et al. ${ }^{57)}$ modeled the non-linear relationship between the geometric variables and welding parameters using the Self-Adaptive Offset Network(SAON). Tarng et al. ${ }^{4)}$ studied relationship between welding parameters and the features of the bead geometry ${ }^{58-59)}$.

Using a back-propagation neural network, they successfully applied a global optimization algorithm to obtain the welding parameters with the optimal bead geometry based on an objective function. Jeng et al. ${ }^{60)}$ predicted the welding parameters in laser butt welding using the back-propagation and Learning Vector Quantization (LVQ) neural network. They considered the input parameters of the neural network to be workpiece thickness and welding gab, while the output parameters was to be the optimal focused position, acceptable welding parameters. Kim et al. ${ }^{61)}$ used the back-propagation neural network to predict bead geometry for GMA welding process. They have shown that the design parameters of the neural network can be chosen from an error analysis, and the developed neural network model can predict the bead geometry with reasonably high accuracy.

They were concluded that the developed neural network was very useful to select suitable welding parameters and to avoid the inappropriate welding design. Son et al. ${ }^{62)}$ verified intelligent models for the lab joint in the

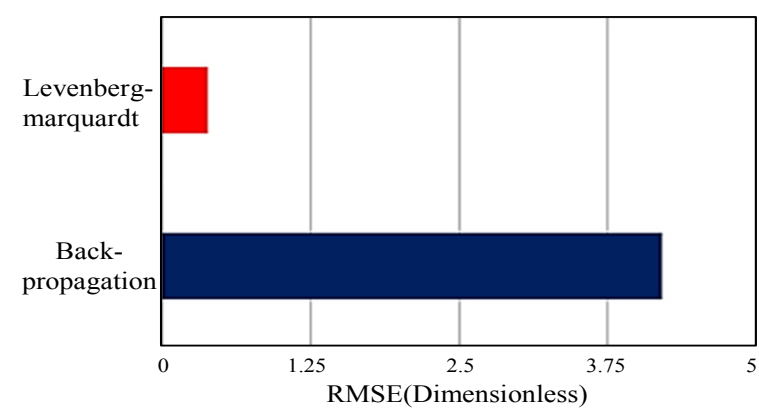

Fig. 6 Comparison between the developed BP and the developed LM neural network models ${ }^{62)}$

robotic GMA welding process by neural network algorithm. Two neural network models which based on BP and LM neural networks, have been developed for studying the effects of process parameters on bead height as welding quality. They successfully applied an artificial intelligence algorithm to obtain the welding parameters with the optimal bead height based on an objective function. Thao et al. ${ }^{63)}$ develop new algorithms based on a full factorial design with two replications to investigate the effects of welding parameters on top-bead width as a function of key output parameters in the robotic GMA welding process. Son et al. ${ }^{64)}$ explored the back-propagation and Levenberg-Marquardt network to associate the welding parameters with the features of the bead width, and concluded that Levenberg- Marquardt networks has better predicting ability than the backpropagation network as shown in Fig. 6.

However, previous most studies as the off-line type models developed for prediction of the bead dimensions for welding quality have been concentrated ${ }^{13)}$. Off-line learning cannot be carried out with new data that acquired at real-time, but on-line learning has a incremental learning method so that on-line learning neural network can be learned with new data during running of neural network model. For the development of full automatic GMA welding system, it should be solved that the predicted model and various sensing system are applied to measure welding quality for searching a reliable sensors. So, the real-time control and monitoring techniques have recently been applied on various welding process $^{65-67)}$.

Especially, many researchers have been developed the real-time predicted model for welding quality using AI methods such as neural network, fuzzy theory ${ }^{66-67)}$. Until now, nobody has attempted to apply on-line learning neural network for the automated arc welding process. Online learning neural network is generally different learning method from off-line learning method which has a bath learning method. Recently, on-line learning neural 


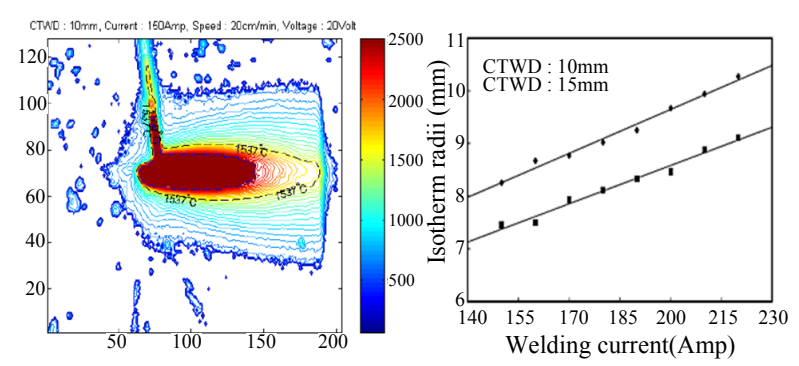

Fig. 7 Comparison between welding current and isotherm radii $^{67)}$

network model with optimal architecture of neural network using genetic algorithm is proposed to be applicable for the real-time prediction of bead geometry ${ }^{68)}$. The on-line learning neural network has been carried out a learning each time data acquired so that on-line learning neural network has a good adaptability more than off-line learning neural network on the other welding circumstances. Also, Kim et al. ${ }^{69)}$ have attempted to employ the isothermal radii to model the various applications of bead geometry in the GMA welding. The possibilities of the Infrared camera in sensing and control of the bead geometry in the automated GMA welding process are presented. Both bead width and thermal images from infrared thermography are affected by welding parameters as presented in Fig. 7.

\subsection{Fuzzy Logic Theory}

Fuzzy logic theory has also been used widely in industry nowadays. During the first decade, many mathematical structures were developed by generalizing the underlying sets to be fuzzy ${ }^{70)}$. These structures include logics, relations, functions, graphs. An example of a classical set and a fuzzy set is indcated in Fig. 8, where the vertical axis represents the degree of membership in a set $^{71)}$. A study on phenomena of the GMA welding process has been a major concern over the years. To describe the essential aspects of a specific system, the investigation of relationship between welding parameters and bead geometry as welding quality has been concentrated until now. But traditional theoretical techniques were too pre-

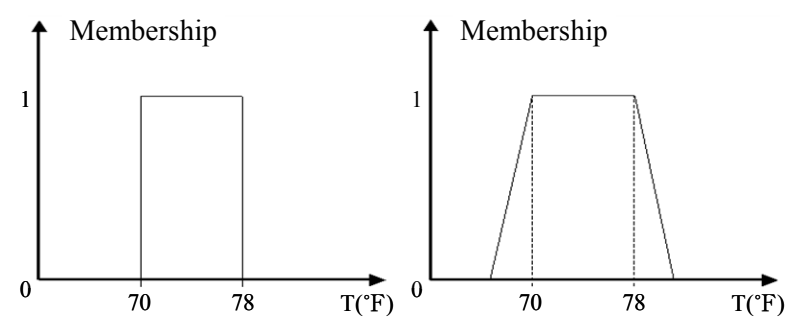

Fig. 7 Comparison between welding current and isotherm $\operatorname{radii}^{67)}$ cise for many complex real-world problems so that fuzzy logic, a part of AI technologies, seems to be a convenient tool to solve problems in some imprecise way ${ }^{72)}$.

Fuzzy set theory, in which vague conceptual phenomena can be precisely and rigorously studied, can be considered as a modeling theory well suited for situations in which fuzzy relations, criteria, and phenomena exist $^{71)}$. Liao et al. ${ }^{74)}$ applied the fuzzy clustering technique to classify and verify the quality of aluminum welds based on the bead geometry. This technique was also employed to improve the welding quality ${ }^{75-77)}$. Kuo ${ }^{76}$ ) using fuzzy theory coupled with image processing techniques to analyze the weldment and to send an appropriate control signal to the numerical control machine to correct the fully automatic GMA welding process.

In his study, fuzzy theory and edge-operator-detection methods were then used to generate the gray level feature factors and the membership function of the image of the actual weldment and welded seam obtained by CCD equipment. This information was input into decision-making logic, which through linear regression, determines the correct weldment. $\mathrm{Li}$ and Srikanthan ${ }^{78)}$ combined both fuzzy logic control and NN techniques together and employed this novel technique to control the GMA welding process. This technique employed overcomes limitations such as the dependency on the experts for fuzzy rule generation and non-adaptive fuzzy set. The adaptations of membership function as well as the self-organizing of fuzzy rule are realized by the self-learning and competitiveness of the NN.

\subsection{Genetic Algorithm}

Stochastic search methods have been employed to solve a difficult problem in science, that's how to find out a vector in vector space $\mathrm{Rn}(\mathrm{n}>3)$ that can satisfy some constraints and provide the optimization. Normally GA(Genetic Algorithm), one of the stochastic search methods, was a powerful tool to solve the optimization problems especially in various welding process. The algorithm encodes a potential solution to a specific problem on a simple chromosome such as data structure, and applies recombination operators to these structures so as to preserve critical information. Correia et al. ${ }^{79)}$ utilized GA to select the near-best values of welding parameters based on geometric characteristics. Canyurt ${ }^{80)}$ developed the Genetic Algorithm Welding Strength Estimation Model(GAWSEM) to estimate the mechanical properties of the welded joint for the brass materials. Correia et al. ${ }^{81)}$ focused on comparison between GA and RSM in determination of the suitable welding parame- 
ters in GMA welding process.

Meran $^{82)}$ represented Genetic Algorithm Welding Current Estimation Model(GAWCEM) and Genetic Algorithm Welding Velocity Estimation Model(GAWVEM) to predict the arc current and welding speed according to the welding environment for the brass material. Kim et. al. ${ }^{81)}$ represents a new algorithm to establish a mathematical model for predicting top-bead width through a neural network and multiple regression methods, to understand relationship between welding parameters and top-bead width, and to predict welding parameters on top-bead width in robotic GMA welding process. Using a series of robotic GMA welding, additional multi-pass butt welds were carried out in order to verify the performance of the multiple regression and neural network models as well as to select the most suitable model.

\section{Conclusions}

In the present work, various techniques for the optimization of welding parameters and the effects of welding parameters on the bead geometry as welding quality in GMA welding process are studied and reviewed. Taguchi analysis can provide definitive information if there is only one response but it does not deal with situations where a number of responses are to be optimized. The summary of research works performed shows that conventional techniques and AI techniques are successfully employed in optimization of welding parameters on bead geometry. In addition, experimental design and optimization are presented to give the experimentalist useful tools in the real experimental situation, as well as the necessary theoretical background.

The observation can be utilized as a guideline document for future research in carrying out optimization of GMA welding process. Form the above presented review of optimization of GMA welding process, it is evident that many researchers applied various methodologies to study the complex interaction of different independent process parameters, but there are no studies that report the application systems engineering concepts such as real-time control techniques for GMA welding process.

\section{Acknowledgements}

This research was supported by Basic Science Research Program through the National Research Foundation of Korea (NRF) funded by the Ministry of Education (No. 2015R1D1A3A01020246).

ORCID: Ill-Soo Kim: http://orcid.org/0000-0002-9936-67600 ORCID: Min-Ho Park: http://orcid.org/0000-0003-1459-2126

\section{References}

1. D. K. Feder, Computers in Welding Technology - A Look at Applications and Potentials, Welding Quality, The Role of Computers, Pergamon Press, (1988), 17-35 https://doi.org/10.1016/B978-0-08-036614-2.50008-1

2. G. E. Cook, K. Andersen and R. J. Barrett, Feedback and Adaptive Control in Welding, Proceedings of the 2nd International Conference on Trends in Welding Research, (1988), 891-903

3. K. E. Mckee, Welding, Robots and Productivity, Welding Journal, 61(9) (1982), 30-25

4. Y. S. Tang, H. L. Tsai and S. S. Yeh, Modelling, Optimization and Classification of Weld Quality in Tungsten Inert Gas Welding, International Journal of Machine Tools and Manufacturing, 39(1999), 1427-1438 https://doi.org/10.1016/S0890-6955(99)00013-9

5. R. L. Brien, Welding Handbook. American Welding Society, 2(1990), 110-155

6. H. B. Cary, Modern Welding Technology, New Jersey. Prentice Hall, (1979), 169-175

7. I. S. Kim, K. J. Son Y. S. Yang and P. K. D. V. Yaragada, Sensitivity Analysis for Process Parameters in GMA Welding Processes Using a Factorial Design Method, International Journal of Machine Tools Manufacturing, (2003), 763-769 https://doi.org/10.1016/S0890-6955(03)00054-3

8. E. Karadeniz, U. Ozsarac and C. Yildiz, The Effect of Process Parameters on Penetration in Gas Metal Arc Welding Process, Materials and Design, 28(2) (2007), 649-656 https://doi.org/10.1016/j.matdes.2005.07.014

9. K. C. Jang, D. G. Lee, J. M. Kuk and I. S. Kim, Welding and Environmental Test Condition Effect in Weldability and Strength of Al Alloy, Journal of Materials Processing Technology, 164(165) (2005), 1038-1045

https://doi.org/10.1016/j.jmatprotec.2005.02.193

10. F. Wang, W. K. Hou, S. J. Hu, E. Kannatey-Asibu, W. W. Schultz and P. C. Wang, Modelling and Analysis of Metal Transfer in Gas Metal Arc Welding, J. Phys. D, Appl. Phys, 36 (2003), 1143-1152 https://doi.org/10.1088/0022-3727/36/9/313

11. P. S. Myers, O. A. Uyehara and G. L. Borman, Fundamentals of Heat Flow in Welding, Welding Research Council Bulletin, 123, (1967)

12. C. R. Heiple and J. R. Roper, The Geometry of Gas Tungsten Arc, Gas Metal Arc and Submerged Arc Weld Beads, Welding, Theory and Practice, Elsevier Science Publishers, (1990), 1-33 https://doi.org/10.1016/B978-0-444-87427-6.50007-1

13. S. J. Marburger, Welding Automation and Computer Control. Welding, Theory and Practices, Elsevier Science Publishers, B. V., (1990), 209-233 https://doi.org/10.1016/B978-0-444-87427-6.50013-7

14. C. E. Jackson, The science of Arc Welding, Welding Journal, 39(6) (1960), 225-230 
15. T. Shinoda and J. Doherty, The Relationship Between Arc Welding Parameters and Weld Bead Geometry, A Literature Survey, The Welding Institute Report, 74 (1978)

16. M. Galopin and E. Boridy, Statistical Experiment in Arc Welding. Advances in Welding Science and Technology, Proceedings of an International Conference on Trends in Welding Research, (1986), 719-722

17. Y. M. Zhang, R. Kovacevic and L. Li, Characterization and Real-Time Measurement of Geometrical Appearance of the Weld Pool, International Journal of Machine Tools and Manufacture, 36(7) (1996), 799-816 https://doi.org/10.1016/0890-6955(95)00083-6

18. P. Hammersberg and H. Olsson, Proactive Control of Weld Dimensions in Robot MAG Welding, (2013)

19. D. Ramos-Jaime, I. L. Juárez and P. Perez, Effect of Process Parameters on Robotic \{GMAW Bead Area Estimation, Procedia Technology, 7, (2013), 398-405 https://doi.org/10.1016/j.protcy.2013.04.050

20. J. C. McGlone, Welding Bead Geometry Prediction A Review, Metal Construction, 14 (7) (1982), 378-384

21. J. Doherty and J. C. McGlone, Relationships Between Process Parameters and Weld Geometry, The Welding Institute Report, 52 (1977)

22. I. S. Kim, J. S. Son, C. E. Park, C. W. Lee and P. K. D. V. Yarlagada, A Study on Prediction of Bead Height in Robotic Arc Welding Using a Neural Network, Journal of Materials Processing technology, 293(6) (2002), 1-6 https://doi.org/10.1016/S0924-0136(02)00803-8

23. K. Abbasi, An Experimental Study on the Effect of MIG Welding Parameters on The Weld-Bead Shape Characteristics, International journal of Engineering Science and Technology, 2(4) (2012)

24. H. S. Gurev and R. D. Stout, Solidification Phenomena in Inert -gas Metal Arc Welds, Welding Journal, 42(7) (1963), 298-310

25. K. Srinivasulu Reddy, Optimization \& Prediction of Welding Parameters and Weld Bead Geometry In Submerged Arc Welding, International Journal of Applied Engineering Research And Development, 3(3) (2013), 1-6

26. G. Haragopal, P. V. R. Ravindra Reddy, G. Chandra Mohan Reddy and J. V. Subrahmanyam, Parametric Design for MIG Welding of Al-65032 Alloy Using Taguchi Technique, Journal of Scientific and Industrial Research, 70(2011), 844-858

27. C. Zhang, G. Zhao, H. Chen, Y. Guan and H. Li, Optimization of An Aluminum Profile Extrusion Process Based on Taguchi's Method with S/N Analysis, International Journal of Advanced Manufacturing Technology, 60(2012), 589-599 https://doi.org/10.1007/s00170-011-3622-x

28. P. K. Ghosh, S. R. Gupta, P. C. Gupta and R. Rathi, Fatigue Characteristics of Pulsed MIG Welded Al-Zn- Mg Alloy, Journal of Material Science, 26(22) (1991), 6161-6170 https://doi.org/10.1007/BF01113899

29. Ø. Langsrud, M. Risberg Ellekjaer and T. Naes, Identifying Significant Effects in Fractional Factorial
Experiments, Journal of Chemometrics, 8(1994) 205219 https://doi.org/10.1002/cem.1180080304

30. N. Alagumurthi, K. Palaniradja and V. Soundararajan, Optimization of Grinding Process Through Design of Experiment (DOE), A Comparative Study, Materials and Manufacturing Processes, 21 (1) (2006), 19-21 https://doi.org/10.1080/AMP-200060605

31. Y. Hsiao, Y. Tarng and W. Huang, Optimization of Plasma Arc Welding Parameters by Using The Taguchi Method with The Grey Relational Analysis, Journal of Materials and Manufacturing Processes, 23 (2008), 51-58 https://doi.org/10.1080/10426910701524527

32. S. Datta, M. Sundar, A. Bandyopadhyay, P. K. Pal, S. C. Roy and G. Nandi, Statistical Modeling for Predicting Bead Volume of Submerged Arc Butt Welds, Australasian Welding Journal, 51 (2006)

33. V. Gunaraj and N. Murugan, Prediction and Optimization of Weld Bead Volume for The Submerged Arc Process - Part 1, Welding Journal, (2000), 286-294

34. V. Gunaraj and N. Murugan, Prediction and Optimization of Weld Bead Volume for The Submerged Arc Process - Part 2, Welding Journal, (2000), 331-338

35. D. Kim, M. Kang and S. Rhee, Determination of Optimal Welding Conditions with a Controlled Random Search Procedure, Welding Journal, (2005)

36. G. Hargopal and P. V. R. Ravindra Reddy, Parameter Design for MIG Welding of Al-65032 Alloy Using Taguchi Technique, Journal of Scientific and Industrial Research, 70(2011), 844-850

37. V. Chauhan, G. Khandoori and A. Kumar, Role of Taguchi Design of Experiment in Optimization of Welding Process Parameters for Different Materials-A Review, International Journal of Advanced Technology \& Engineering Research (IJATER), (2014), 146-151

38. I. S. Kim, J. S. Son, C. E. Park, I. J. Kim and H. H. Kim, An Investigation Into An Intelligent System for Predicting Bead Geometry in GMA Welding Process, Journal of Materials Processing Technology, 159(1) (2005), 113-118 https://doi.org/10.1016/j.jmatprotec.2004.04.415

39. U. Esme, M. Bayramoglu, Y. Kazancoglu and S. Ozgun, Optimization of Weld Bead Geometry in Tig Welding Process Using Grey Relational Analysis and Taguchi Method, Materials and Technology, 43 (2009), 143- 149

40. J. Kim, K. Park, Y. Hwang and I. Park, Sustainable Manufacturing, A Case Study of The Forklift Painting Process, International Journal of Production Research, 48(10) (2010), 3061-3078 https://doi.org/10.1080/00207540902791785

41. S. B. Jones, Process Tolerance in Submerged Arc Welding, Initial Report, The Welding Institute Report, 1 (1976)

42. J. C. McGlone, The Submerged Arc Butt Welding of Mild Steel Part 1 : The Influence of Procedure Parameters on Weld Bead Geometry. The Welding Institute Report, 79 (1978) 
43. J. C. McGlone and D. B. Chadwick, The Submerged Arc Butt Welding of Mild Steel Part 2 : The Prediction of Weld Bead Geometry From The Procedure Parameters. The Welding Institute Report, 80 (1978)

44. J. Doherty, T. Shinoda and J. Weston, The Relationships Between Arc Welding Parameters and Fillet Weld Geometry for MIG Welding with Flux Cored Wires. The Welding Institute Report, 82 (1978)

45. S. Pandey and R. S. Parmar, Mathematical Models for Predicting Bead Geometry and Shape Relationships for MIG Welding of Aluminium Alloy 5083. Recent Trends in Welding Science and Technology, TWR '89, Proceedings of the 2nd International Conference on Trends in Welding Research, (1989), 37-41

46. J. Raveendra and R. S. Parmer, Mathematical Models to Predict Weld Bead Geometry for Flux Cored Arc Welding, Metal Construction, 19(2) (1987), 31-35

47. R. S. Chandel, Mathematical Modelling of Gas Metal Arc Weld Features. Modeling and Control of Casting and Welding Processes IV, Proceedings of the Fourth International Conference on Modeling of Casting and Welding Processes, (1988), 109-120

48. L. J. Yang, R. S. Chandel and M. J. Bibby, The Effects of Process Variables on The Bead Height of SubmergedArc Weld Deposits, Canadian Metallurgical Quarterly, 31(4) (1992), 289-297 https://doi.org/10.1179/cmq.1992.31.4.289

49. M. H. Park, I. S. Kim, J. P. Lee, D. H. Kim, B. J. Jin, I. J. Kim and J. S. Kim, Sensitivity Analysis for Prediction of Bead Geometry Using Plasma Arc Welding in Bellows Segment, International Journal of Engineering Research \& Science, 2(4) (2016), 154-161

50. J. S. Kim, J. P. Lee, M. H. Park, C. K. Park and I. S. Kim, A Study on Prediction of The Optimal Process Parameters for GMA Root-Pass Welding in Pipeline. Procedia Engineering, 97 (2014), 723-731 https://doi.org/10.1016/j.proeng.2014.12.302

51. I. S. Kim, M. H. Park, H. H. Kim, J. P. Lee, C. K. Park and J. Y. Shim, An Experimental Study on Mathematical Model to Predict Bead Width in GMA Weldment, International Journal of Precision Engineering and Manufacturing, 32(2) (2015), 209-217. https://doi.org/10.7736/KSPE.2015.32.2.209

52. M. L. Minsky and S. A. Papeat, Perceptions. Cambridge, MA: MIT Press, (1969)

53. J. A. Freeman and D. M. Shapura, Neural Networks Algorithms, Applications and Programming Techniques. New York, NY: Addison-Wesley, (1991)

54. L. Burke and J. P. Ignizio, A Practical Overview of Neural Networks, Journal of Intelligent Manufacturing, 8(1997), 157-165 https://doi.org/10.1023/A:1018513006083

55. S. C. Juang, Y. S. Tarng and H. R. Lii, A Comparison Between The Back-Propagation and Counter-Propagation Networks in The Modelling of The TIG Welding Pro- cess, Journal of Materials Process Technology, 75 (1998), 54-62

https://doi.org/10.1016/S0924-0136(97)00292-6

56. D. S. Nagesh and G. L. Datta, Prediction of Weld Bead Geometry and Prediction in Shielded Metal-Arc Welding Using Artificial Neural Networks, Journal of Materials Process Technology, 79 (2002), 1-10 https://doi.org/10.1016/S0924-0136(02)00101-2

57. P. Li, M. T. C. Fang and J. Lucas, Modelling of Submerged Arc Welding Bead Using Self-Adaptive Offset Neural Network, Journal of Materials Process Technology, 71 (1997), 228-298 https://doi.org/10.1016/S0924-0136(97)00087-3

58. J. P. Lee, I. S. Kim, M. H. Park, C. K. Park, B. Y. Kang and J. Y. Shim, A Study on Development of STACO Model to Predict Bead Height in Tandem GMA Welding Process, Journal of KWS, 32(6) (2014), 22-28 https://doi.org/10.5781/JWJ.2014.32.6.8

59. Y. S. Kim, I. S. Kim, J. H. Lee, S. M. Jung, J. P. Lee, M. H. Park and R. C. Reenal, A Study on Bead Geometry Prediction the GMA Fillet Welding using Genetic Algorithm, Journal of KWS, 30(6) (2012), 126-132 https://doi.org/10.5781/KWJS.2012.30.6.612

60. J. Y. Jeng, T. F. Mau and S. M. Leu, Prediction of Laser Butt Joint Welding Parameters Using Back-Propagation and Learning Vector Quantisation Networks, Journal of Materials Process Technology, 99 (2000), 207-218 https://doi.org/10.1016/S0924-0136(99)00424-0

61. I. S. Kim and C. E. Park, Use of a Neural Network to Control Bead Width in GMA Welding, Welding Research Supplement of the Australian Welding Journal Welding Research Supplement, 45(3) (2000), 33-37

62. J. S. Son, M. H. Park, B. J. Jin, T. J. Yun and I. S. Kim, A Study on Modeling and Controlling Bead Height in The Robotic GMA Welding, International Journal of Applied Engineering Research, 12(13) (2017), 3631- 3638

63. D. T. Thao, I. S. Kim, H. H. Na, S. M. Jung and J. Y. Shim, Development of Mathematical Model with A Genetic Algorithm for Automatic GMA Welding Process, The International Journal of Advanced Manufacturing Technology, 5(8) (2014), 837-847 https://doi.org/10.1007/s00170-014-5842-3

64. J. S. Son, M. H. Park, B. J. Jin, T. J. Yun, J. Y. Shim and I. S. Kim, A Study on New Method for Control to Bead Width using Infrared Sensors. International Journal of Engineering Research And Management, 4(4) (2017) $42-48$

65. Y. W. Park, H. S. Park, S. H. Rhee and M. J. Kang, Real Time Estimation of $\mathrm{CO}_{2}$ Laser Weld Quality for Automotive Industry, Optics \& Laser Technology, 34 (2) (2002), 135-142 https://doi.org/10.1016/S0030-3992(01)00103-7

66. J. Mirapeix, A. Cobo, O. M. Conde, C. Jauregui and J. M. Lopez-Higuera, Real-Time Arc Welding Defect Detection Technique by Means of Plasma Spectrum 
Optical Analysis, NDT \& E International, 39(5) (2006), 356-360 https://doi.org/10.1016/j.ndteint.2005.10.004

67. C. H. Tsai, K. H. Hou and H. T. Chuang, Fuzzy Control of Pulsed GTA Welds by Using Real-Time Root Bead Image Feedback, Journal of Materials Processing Technology, 176 (2006), 158-167 https://doi.org/10.1016/j.jmatprotec.2006.02.027

68. J. S. Son, J. P. Lee, M. H. Park, D. H. Kim, B. H. Jin, K. S. Ki, C. G. Kim and I. S. Kim, A Study On-line Mathematical Model to Control of Bead Width for Arc Welding Process, International Scientific Journal published monthly by the World Academy of Materials and Manufacturing Engineering, 72(2) (2015), 78-85 https://doi.org/10.1016/j.proeng.2017.01.146

69. I. S. Kim, K. S. Chon, J. S. Son, J. H. Seo, H. H. Kim and J. Y. Shim, A Study on Monitoring for Process Parameters using Isotherm Radii. Journal of Welding and Joining, 24(5) (2006) 385-390

70. J. Yen and R. Langari, Fuzzy Logic Intelligence, Control, and Information, New Jersy, Prentice-Hall, Inc. (1999)

71. M. Togai, and H. Watanabe, Expert Systems on Chip, An Engine for Real-Time Approximate Reasoning, IEEE Expert, 1(1986), 55-62 https://doi.org/10.1109/MEX.1986.4306980

72. B. Kosko, Neural Networks and Fuzzy Systems, New Jersey, Prentice Hall, (1992)

73. R. R. Silva and L. P. Caloba, Pattern Recognition of Weld Defects Detected by Radiographic Test, NDT\&E International, 37 (2004), 461-470 https://doi.org/10.1016/j.ndteint.2003.12.004

74. T. W. Liao, D. M. Li and Y. M. Li, Detection of Welding Flaws from Radio-graphic Images with Fuzzy Clustering Methods, Fuzzy Sets and Systems, 108(1999), 145-158 https://doi.org/10.1016/S0165-0114(97)00307-2

75. W Pedrycz And G. Vukovich, Fuzzy Clustering with Supervision, London, Pattern Recognition, (2003) https://doi.org/10.1016/j.patcog.2003.11.005
76. H. C. Kuo and L. J. Wu, An Image Tracking System for Welded Seams Using Fuzzy Logic, Journal of Materials Processing Technology, 120 (2002), 169-185 https://doi.org/10.1016/S0924-0136(03)00702-7

77. K. W. Ip, C. K. Kwong and Y. W. Wong, Fuzzy Regression Approach to Modelling Transfer Moulding for Microchip Encapsulation, Journal of Materials Processing Technology, 140 (2003), 147-151 https://doi.org/10.1016/S0924-0136(03)00702-7

78. D. Li and T Srikanthan, Neural-Network-Based SelfOrganized Fuzzy Logic Control for Arc Welding. Engineering Applications of Artificial Intelligence, 14, 115124 https://doi.org/10.1016/S0952-1976(00)00057-9

79. D. S. Correia, C. V. Gonçalves, Sebastião S. C. Junior and V. A. Ferraresi, GMAW Welding Optimization Using Genetic Algorithms, Presented at COBEF 2003 - II Brazilian Manufacturing Congress, (2003), 18-21 https://doi.org/10.1590/S1678-58782004000100005

80. O. E. Canyurt, Estimation of Welded Joint Strength Using Genetic Algorithm Approach, International Journal of Mechanical Sciences, 47(8) (2005), 1249-1261 https://doi.org/10.1016/j.ijmecsci.2005.04.001

81. D. S. Correia, C. V. Gonçalves, S. S. D. C. Jr and V. A. Ferraresi, Comparison Between Genetic Algorithms and Response Surface Methodology in GMAW Welding Optimization, Journal of Materials Processing Technolog, 160(1) (2005), 70-76 https://doi.org/10.1016/j.jmatprotec.2004.04.243

82. C. Meran, Prediction of The Optimized Welding Parameters For The Joined Brass Plates Using Genetic Algorithm, Materials \& Design, 27(5) (2006), 356-363 https://doi.org/10.1016/j.matdes.2004.11.004

83. I. S. Kim, J. S. Son and P. K. D. V. Yarlagadda, A Study on The Quality Improvement of Robotic GMA Welding Process, Robotics and Computer Integrated Manufacturing, 19 (2003), 567-572 https://doi.org/10.1016/S0736-5845(03)00066-8 